\title{
14 \\ THE COMPUTERIZATION OF SERVICE: Evidence of Information and Communication Technologies in Real Estate
}

\author{
Steve Sawyer \\ College of Information Sciences and Technology \\ Pennsylvania State University \\ University Park, PA U.S.A. \\ Fuyu Yi \\ College of the Liberal Arts \\ Pennsylvania State University \\ University Park, PA U.S.A.
}

\begin{abstract}
We explore the overlap between service and computerization using macro-level industrial data on the U.S. real estate market and five comparison industries (hospitals, financial services, legal services, machinery manufacturing, and fabricated metals). The macro-level data comes from the U.S. Bureau of Economic Analysis and the U.S. Census Bureau and we use it to develop insights on computerization and service relative to contributions to the U.S. gross domestic product. This analysis shows that while information and communication technology investments in real estate lagged comparison industries from 1969 to 1997, since then ICT investments in real estate have increased rapidly. At the same time, there has been a growth in the number workers even as the industry's contribution to GDP has grown. We identify two implications of these findings. First, ICTs are not being used are not as a substitute for labor. Second, the rapid growth in ICT investments has been absorbed into real estate quickly and well. Still, computerization in real estate continues, suggesting that process studies and more micro-analyses are critical next steps.
\end{abstract}

Keywords Service, computerization, real estate, secondary data

Please use the following format when citing this chapter:

Sawyer, S., and Yi, F., 2008, in IFIP International Federation for Information Processing, Volume 267, Information Technology in the Service Economy: Challenges and Possibilities for the $21^{\text {st }}$ Century, eds. Barrett, M., Davidson, E., Middleton, C., and DeGross, J. (Boston: Springer), pp. 198-209. 


\section{INTRODUCTION}

In this paper, we draw on data regarding the take up and uses of information and communication technologies (ICTs) in the U.S. real estate and five other industries to speculate on implications for services sciences (Chesbrough and Spohrer 2006). We see the take up and uses of ICT as core to both computerization (e.g., Burris 1998) and to services (e.g., Rust and Miu 2006; Sheehan 2006). We define a service as the change in one's state - or the state of goods that one owns - brought about from activity of others, and jointly consummated. Our definition reflects elements common to the many definitions of service: the joint or mutual engagement by service provider and service consumer, the importance of knowledge in consummating the service action, a temporal connection between production and consumption of the service, the potential for the service to involve tangible and intangible goods, and reliance on ICTs.

This definition of service also makes explicit that shaping and sharing information among providers and services consumers is a core element of the coconstructed nature of a service. For that reason we draw on the work of real estate agents as an exemplar of informational service. We focus attention on the U.S. real estate industry as the rapid rise in the uses of ICT has been both visible and hotly debated. In 1997, very few real estate agents posted their listings online and very few consumers used online resources to pursue buying and selling of houses. In 2007, online access to house and housing information was extensive, with reports that more than 70 percent of all consumers began their house-hunting process by going online.

The contribution of this paper is to theorizing on the computerization of service. We use the evidence from the real estate market to raise issues relative to both the take up and uses of ICT in supporting services. To do this, we use macro-level data to develop a comparison of the take up and uses of ICT in real estate and five other industries: two manufacturing activities and three other professional services industries. Our comparison focuses on ICT investment, employment, and value-added to the U.S. gross domestic product over time.

This paper continues in three sections. In the next section, we report the selection of industries and data, and we explain the approach used to do the comparative analysis in these industries. In the third section, we report findings from this analysis. In the fourth section, we discuss these findings, speculate on their implications, and suggest future work.

\section{RESEARCH APPROACH}

In order to have a broader and at the same time representative set of industries for investigation, we selected real estate and five other industries using the 2002 U.S. North American Industry Classification System (NAICS) codes. ${ }^{1}$ We chose three informationintensive and service-oriented industries (similar to real estate) and two more traditional manufacturing industries (to provide for comparison). For the two manufacturing industry sectors, we use fabricated metal products and machinery/manufacturing. These are mature industries, ones that have experienced tremendous changes in base technologies

${ }^{1}$ For information on the NAICS codes, see http://www.census.gov/epcd/naics02/. 
over the past 100 years, but little change in the past 30 years. Including these industries provides a basis of comparison between real estate (as an information-intensive service industry) and classic industrial activity regarding computerization.

For services-oriented industries, we selected three that are also information-intensive: legal services, financial services (securities, commodity contracts, and investments), and hospitals. The service industries selected for comparison with real estate differ on the level of professionalization (e.g., the need for college or graduate degrees, extensive professional certification) relative to trades (that may or may not demand certification but likely require some level of training. We selected hospitals because this industrial sector also has also rapidly computerized. ${ }^{2}$

\subsection{Data}

We use secondary data because it is available and primary data is not. Secondary data at the industry level is often available from specific industrial trade associations (such as the National Association of Realtors and the American Manufacturing Association). However, these data are often proprietary, use different (and possibly incompatible) measures, and follow different procedures to gather; some industrial sectors do not have comprehensive associations or data collection. Another source of secondary data are nongovernmental agencies such as the Organisation of Economic Cooperation and Development (OECD), ${ }^{3}$ which provides yearly reports by industry regarding a range of ICT expenditures.

A third source of secondary data is the U.S. federal government. For example, the Census Bureau provides data about ICT expenditures for the previous two years by industry and this is summarized in the bi-annual "Information and Communication Technology" report, with the most recent being released in April, 2007. ${ }^{4}$ The U.S. Bureau of Economic Analysis (BEA) provides historical data on ICT expenditures by industry and so we chose to draw on their data, as detailed below. ${ }^{5}$

The first source of data used in this analysis is the BEA's "Historical-Cost Investment in Private Nonresidential Fixed Assets." The estimates are presented for detailed industries by asset type. The second source of data is the BEA's "GrossDomestic-Product-(GDP)-by-Industry" data set. The BEA defines the value-added of an industry as "the gross output of an industry or a sector less its intermediate inputs; the contribution of an industry or sector to gross domestic product (GDP)." We use industry value-added to compare industries, acknowledging as we do that this is a granular measure. For this analysis, the focus is on change in value-add over time and change in value-add relative to investments in ICT. Third, we use the BEA's tables of industry employment based on full-time equivalents (FTE). Full-time and part-time employees

\footnotetext{
${ }^{2} \mathrm{We}$ chose not to include in this comparative analysis either insurance carriers or travel agents, as these industries focus more on commodity sales (an airline ticket or insurance policy is more a commodity than is a house).

${ }^{3}$ Information on the OECD is available at http://www.oecd.org/.

${ }^{4}$ The Census Bureau's report, "Information ad Communication Technology: 2005," issued in April 2007, is available at http://www.census.gov/prod/2007pubs/ict-05.pdf.

${ }^{5}$ The information on the BEA in the following paragraph was obtained from its website, http://www.bea.gov/national/.
} 
by industry are the number of employees on full-time schedules plus the number of employees on part-time schedules. FTE employees by industry are the number of employees on full-time schedules plus the number of employees on part-time schedules converted to a full-time basis. The number of FTE employees in each industry is the product of the total number of employees and the ratio of average weekly hours per employee for all employees to average weekly hours per employee on full-time schedules.

The time-range used for analysis spans 1969 to the latest available data (either 2005 or 2006). We chose 1969 because in this year IBM was forced to unbundle hardware from software (Carmel 1997; Wolff 2002). This unbundling triggered a rapid growth in IT investments across many industries and sectors of the economy. We provide separate tables for the subset of this period spanning 1997-2005/2006 because 1997 was the year when much of the multiple listing services data on homes was first made available via the Internet (on www.realtor.com), making this a watershed point in the computerization efforts in this industry. For the industries we are comparing, BEA value-add data are only available for the period 1977 to 2005 . Relative to the occupational employment and wage estimate data, in order to achieve consistency in industrial comparison over time, we use NAICS FTE data for the period 1998-2005.

\subsection{Analysis}

We present our analysis in four figures. In Figures 1 through 3, we present data plotted against time ${ }^{6}$ for each of the six industries. In Figure 4 , we present the valueadded by industry using chained value data to provide evidence of value-added by industry while accounting for inflation.

\section{FINDINGS}

Trends identified in the figures are summarized in Tables 1 and 2 and discussed below. We conclude this section by discussing three findings which we summarize in Table 3 and discuss below.

The summary provided in Table 1 makes clear that the real estate industry has been investing more in ICT since 1997 relative to the comparison group of industries. This is a marked change from the previous 30 years. The summary provided in Table 2 makes clear that the value-added (to GDP) by the real estate industry has increased relative to the comparison industries since 1997, and compares favorably with other service and information-intensive industries over the entire period for which we have data. There is a large, significant, and positive correlation between investments in ICT and increased value-added for all six industries. ${ }^{7}$

${ }^{6}$ The BEA also produces chain-type quantity indexes for investment in order to account for inflation over time. However, the price for computer and related products is decreasing dramatically over time. As a result, inflation is not a central concern.

${ }^{7}$ Pearson correlations (two-tailed, all significant at $\mathrm{p} \leq 0.01$ ) are real estate $=0.872$; legal services $=0.968$; securities, commodity contracts, and investments $=0.544$; hospitals -0.990 ; fabricated metal products $=0.977$; and machinery $=0.940$. Correlations cannot imply causations. 


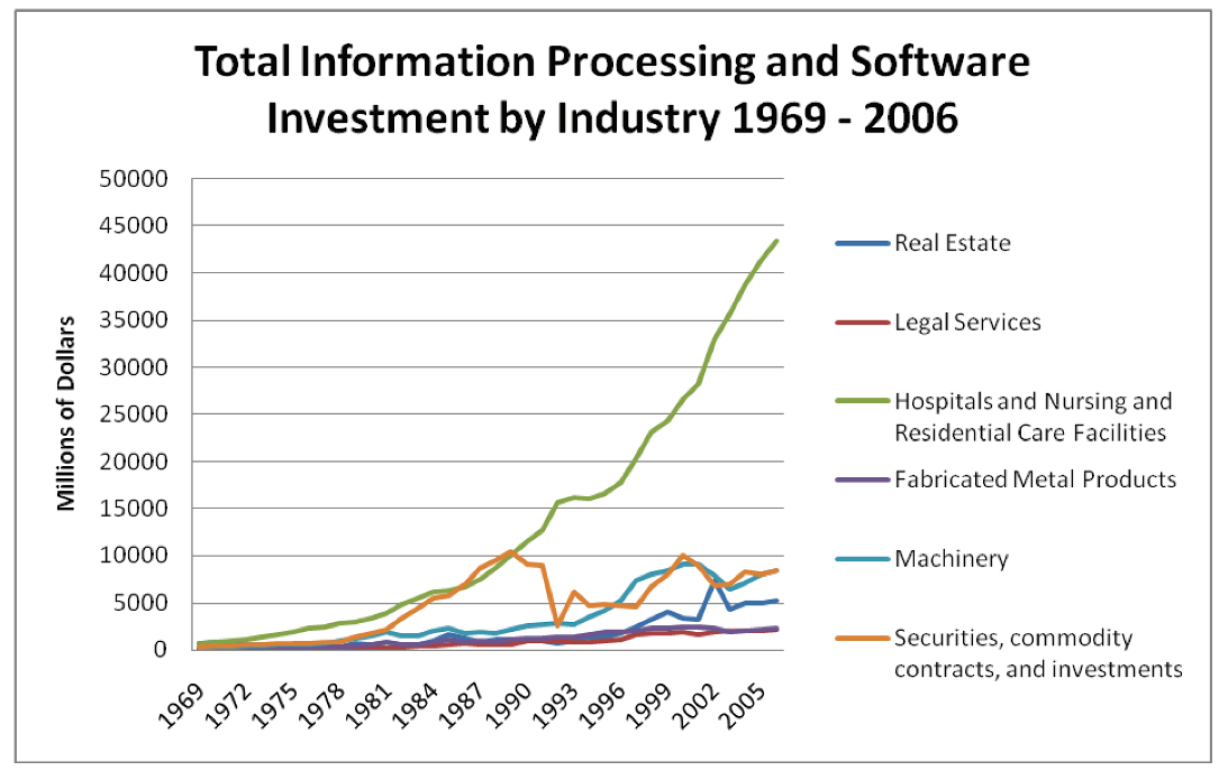

Figure 1. Total ICT (Equipment and Software) Investments by Industrial Sector (1969-2006). (Source: Historical-Cost Investment in Private Nonresidential Fixed Assets, BEA, http://www.bea.gov/national/FA2004/Details/Index.html)

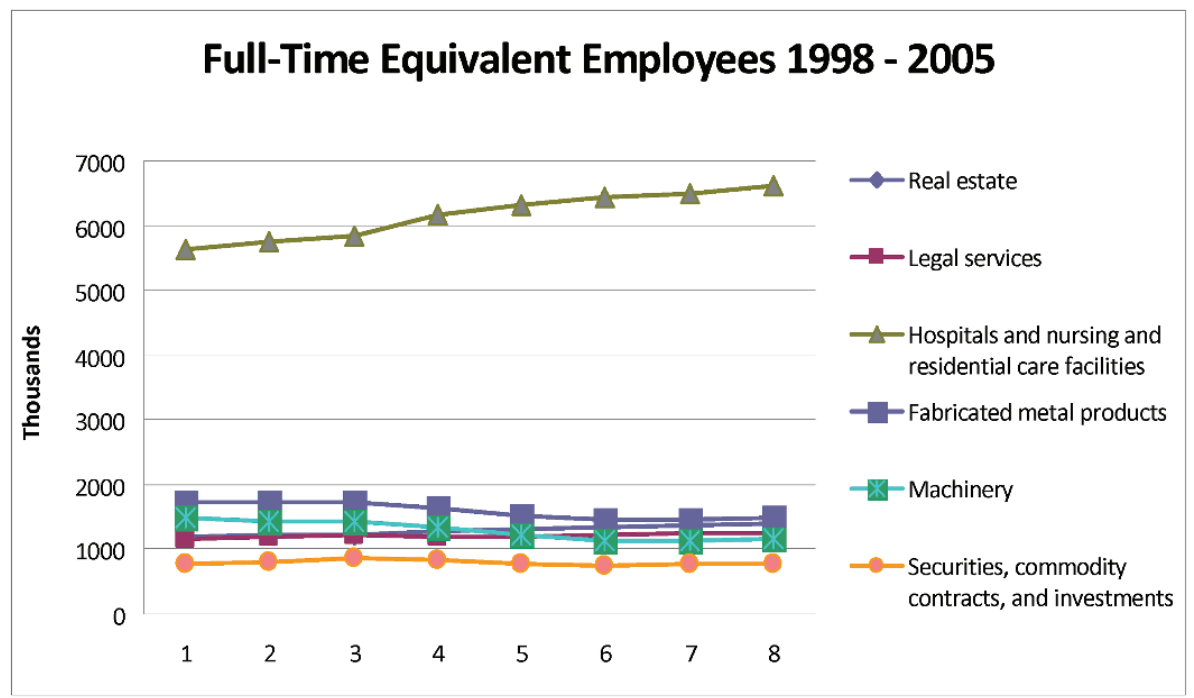

Figure 2. Full-Time Equivalent (FTE) Employment by Industrial Sector (19982006) (Source: Full-Time Equivalent Employees by Industry, Gross-DomesticProduct-by-Industry Accounts, 1947-2006, BEA) 


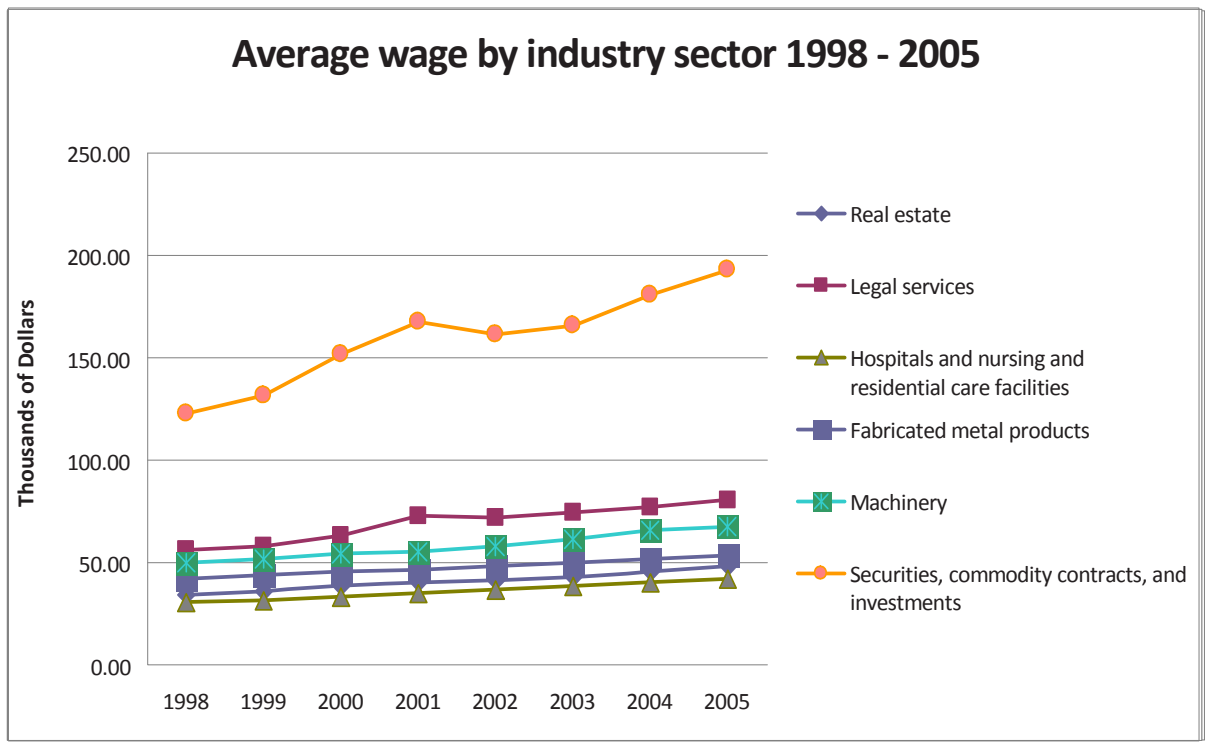

Figure 3. Average Wage by Industrial Sector (1998-2005) (Source: Full-Time Equivalent Employees by Industry, Gross-Domestic-Product-by-Industry Accounts, 1947-2006, and Components of Value Added by Industry Group, Gross- DomesticProduct-By-Industry Accounts, 1947-2006, BEA)

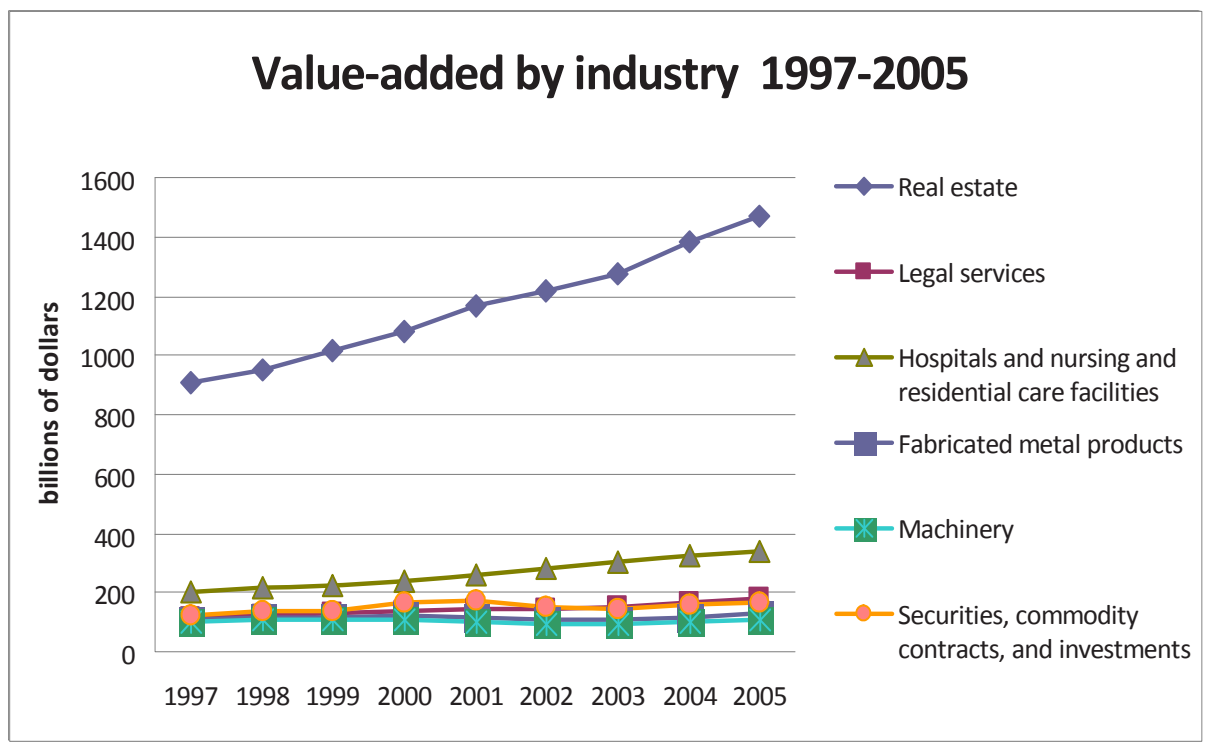

Figure 4. Value-Added (Chained Value) by Industrial Sector (with 2000 as Base), 1997-2005 (Source: Real Value Added by Industry, Gross-Domestic-Product-byIndustry Accounts, 1947-2006, BEA) 
Table 1. Summary of ICT Investment Over Time for Six Comparative Industries

\begin{tabular}{|l|c|c|c|c|c|c|}
\hline \multicolumn{1}{|c|}{ Industry } & \multicolumn{2}{c|}{$\mathbf{1 9 6 9 - 1 9 9 7}$} & \multicolumn{2}{c|}{$\mathbf{1 9 9 7 - 2 0 0 5}$} & \multicolumn{2}{c|}{$\mathbf{1 9 6 9 - 2 0 0 5}$} \\
\hline & Ranking & $\begin{array}{c}\text { Average } \\
\text { Rate }\end{array}$ & Ranking & $\begin{array}{c}\text { Average } \\
\text { rate }\end{array}$ & Ranking & $\begin{array}{c}\text { Average } \\
\text { rate }\end{array}$ \\
\hline Real estate & $\mathbf{6}$ & $\mathbf{7 . 8 6 \%}$ & $\mathbf{1}$ & $\mathbf{1 3 . 3 7 \%}$ & $\mathbf{6}$ & $\mathbf{1 5 . 6 2 \%}$ \\
\hline Legal services & 1 & $146.98 \%$ & 4 & $3.77 \%$ & 2 & $149.64 \%$ \\
\hline $\begin{array}{l}\text { Hospitals and nursing and } \\
\text { residential care facilities }\end{array}$ & 2 & $99.77 \%$ & 2 & $12.92 \%$ & 1 & $160.65 \%$ \\
\hline Fabricated metal products & 5 & $56.15 \%$ & 6 & $0.42 \%$ & 5 & $45.24 \%$ \\
\hline Machinery & 3 & $76.47 \%$ & 5 & $1.06 \%$ & 4 & $64.75 \%$ \\
\hline $\begin{array}{l}\text { Securities, commodity } \\
\text { contracts, and investments }\end{array}$ & 4 & $61.30 \%$ & 3 & $9.92 \%$ & 3 & $87.73 \%$ \\
\hline
\end{tabular}

Table 2. Value-Added Change Over Time for Six Comparison Industries

\begin{tabular}{|l|c|c|c|c|c|c|}
\hline \multicolumn{1}{|c|}{ Industry } & \multicolumn{2}{c|}{$\mathbf{1 9 7 7 - 1 9 9 7}$} & \multicolumn{2}{c|}{$\mathbf{1 9 9 7 - 2 0 0 6}$} & \multicolumn{2}{c|}{$\mathbf{1 9 7 7 - 2 0 0 6}$} \\
\hline & Ranking & $\begin{array}{c}\text { Average } \\
\text { Rate }\end{array}$ & Ranking & $\begin{array}{c}\text { Average } \\
\text { Rate }\end{array}$ & Ranking & $\begin{array}{c}\text { Average } \\
\text { Rate }\end{array}$ \\
\hline Real estate & $\mathbf{4}$ & $\mathbf{1 8 . 1 7 \%}$ & $\mathbf{2}$ & $\mathbf{7 . 7 7 \%}$ & $\mathbf{4}$ & $\mathbf{2 3 . 2 7 \%}$ \\
\hline Legal services & 2 & $28.21 \%$ & 3 & $7.25 \%$ & 2 & $33.91 \%$ \\
\hline $\begin{array}{l}\text { Hospitals and nursing and } \\
\text { residential care facilities }\end{array}$ & 3 & $24.60 \%$ & 1 & $8.51 \%$ & 3 & $31.97 \%$ \\
\hline Fabricated metal products & 5 & $9.70 \%$ & 5 & $2.59 \%$ & 5 & $9.11 \%$ \\
\hline Machinery & 6 & $6.01 \%$ & 6 & $1.66 \%$ & 6 & $5.34 \%$ \\
\hline $\begin{array}{l}\text { Securities, commodity } \\
\text { contracts, and } \\
\text { investments }\end{array}$ & 1 & $90.03 \%$ & 4 & $5.01 \%$ & 1 & $91.53 \%$ \\
\hline
\end{tabular}

Finding \#1: Total ICT investments in real estate lagged most comparison industries until the late 1990s; since then it has been a leader. As depicted in Figure 1, total ICT investments in real estate lagged behind the comparison industries over the period 1969 to 2005 . Over this time, total ICT investment in real estate grew at an annual rate of 6 percent per year. This stands in contrast to IT investment in hospitals, which grew at an average annual rate of 12 percent per year over the same period. However, as detailed in Table 1, over the last 10 years, the investments in ICT in real estate have grown substantially, moving real estate into the top of the comparison group of industries. There have been large increases in investments in both ICT equipment and software, and a growth in the number of ICT workers as a percentage of total FTE in real estate. Data in Figure 1 shows that total ICT investments in real estate rose rapidly in the 1990s relative to comparison industries.

Relative to investments in software, real estate is the industry with the most dramatic changes over the period 1969-2005. The first period of rapid change (from 5 percent in 1977 to 24 percent in 1980) is followed by a sharp decrease. A period of steady growth in the 1980s (from 5 to 10 percent per year of ICT investment in software) is followed by explosive growth (63 percent in 1992), dropping to between 33 and 40 percent of total ICT investment spending since. 
Data presented in Figure 4 and Table 1 provide evidence that the value added to GDP by real estate is both substantial and increasing, even as ICT investments are growing. This is true for all other comparison industries, although the growth is greatest in the service industries. Real estate's value-adding growth is larger than inflation and, since 1997, greater than all comparison industries save for hospitals. This suggests that the real estate industry has been able to turn ICT investments into additional value-added at a rate greater than the other comparison industries. This stands in contrast to industries in this comparison group such as hospitals, which have had much larger investments in ICT but not the seven-fold increase in value added (since 1977).

Finding \#2: Real estate FTE growth is the least of all service industries in the comparison group. Data in Figure 2 show that FTE employment in real estate has grown steadily at about 1.9 percent per year since 1969 . The securities industry has had the largest growth (about 4.5 percent per year) and legal services industry has been the second largest (at 3.3 percent per year). Hospitals have also been growing (at about 2.8 percent per year over the period 1969-2005). Both fabricated metal products and machinery have a similar and general slightly downward trend. Moreover, compensation per FTE has been rising in all six comparison industries, with real estate similar to traditional manufacturing levels, and well below securities. The real estate average per FTE in 2005 was slightly greater than $\$ 50,000$, or one-quarter of the average compensation per FTE in the securities industry.

\section{DISCUSSION, IMPLICATIONS, AND FUTURE WORK}

Building on the findings (summarized in Table 3), we discuss two implications. First, the modest growth of FTE in real estate, combined with the rapid computerization, suggests that computing is not being engaged as a labor-capital substitution. The second implication we raise is that while the take up and uses of ICT in real estate have been quickly absorbed, the effects of this take up and uses of ICT in real estate remain indeterminate.

We further note that the granularity of the secondary data and issues with measuring ICT. ${ }^{8}$ Despite these concerns, such comparisons are common. Dumagan et al. (2002) and Wolff (2003), in fact, come to different findings on the roles that ICTs play in industry-level performance. Wolff finds little direct impact of investments in ICTs, save for the restructuring of work and production. Dumagan et al. find that spending on ICT does lead to industry-level differences in productivity, with services that invest more in ICT outperforming those that invest less. Still, these multiple interpretations suggest caution when relying solely on analysis and interpretation of secondary data.

Implication \#1: Modest growth of FTE in real estate relative to rapid computerization. Data show there is growth in both ICT investment and FTE in all service industries. This pattern seems counter to the labor/capital substitution relationship that was (and remains) very clear in manufacturing and is often assumed as a basis for ICT investments. In contrast to this, we offer three possible reasons for the growth in both ICT investment and FTE in real estate, and more broadly for information services.

${ }^{8}$ Micro-level analyses such as those developed by Crowston et al. (2001) and Sawyer et al. (2003) help to interpret this macro-level data. 


\section{Table 3. Summary of Findings}

1. Total ICT investments in real estate lagged most comparison industries until the late 1990s; since then, it has been a leader.

2. Real estate growth is the least of all service industries in the comparison industries.

The first reason for this dual growth may be that this is a transient artifact of the change-over from human-centered to more computing-centered work processes. The transient argument contends that FTE will drop away as ICTs begin to replace human knowledge work (like programmed trading, automated ticketing, or artificially intelligent loan originating decisions). However, using ICTs to replace knowledge work (as opposed to physical work) seems to be more complicated, particularly when the work flow is difficult to specify and very contingent, as it is in real estate (e.g., Crowston et al. 2001).

A second reason may be that there is a surge of FTE and ICT investment related to a particular technological innovation, and, when it is no longer new, ICT investment and FTE will drop. However if there is constant innovation and ongoing introduction of new ICTs, there may be a consistent need for new skills and more people to deploy and maintain the new ICTs. This means that FTE and ICT growth is not a temporary activity.

A third reason may be that take up and uses of ICT for known goals (so-called firstlevel effects) give way to uses of ICT for things not first imagined (the "second-level" effects; Sproul and Kiesler 1991). This suggests that ICT for informational services may be best seen as platform investments (e.g, Ciborra 1996).

Implication \#2: ICTs have been absorbed into real estate quickly and well. Despite rapid increases in ICT investments since 1997, the real estate industry seems to have been able to absorb changes and innovations that arise from their take up and uses (when evaluated against the increasing value-added contribution to GDP over the same time). There are at least three reasons. First, it may be that the ICTs being taken up and used in real estate are so simple that there is a very small learning curve for any one individual. This translates into a short lag time between taking-up the new ICT to value creation, particularly when compared to other industries. A derivative of this reasoning may be that the tasks for which the ICTs are being used are also simple. However, the simple-tasks/simple-uses reasoning fails to account for the rise in FTEs and has no supporting empirical evidence.

A second reason to explain why ICTs have been absorbed into real estate so quickly may be due in part to the industry's communal investments in a shared information infrastructure embodied in the sharing of house listing data available in the 900 plus local multiple listing services (MLS) through common public portals. Data in Figures 1 and 2 suggest that there were extensive ICT investments in the late1990s, consistent with the time during which most local MLS invested in larger-scale digital and computing infrastructures to bring their agent's house-listing data online. This shared information infrastructure is a unique attribute of residential real estate that builds on the extensive history of the local and regional MLS, and the series of changes in real estate practices that have been engendered in part by the availability of online MLS access (see Sawyer et al. 2005). The implication of this reasoning for other information-centric services is 
that the specific and unique nature of real estate's information sharing infrastructure is critical to understanding

A third reason for this successful take up and use of ICTs into real estate may be a combination of both changing social experiences and the locus of innovation and change. By changing social experiences, we note that over the same time period (1997-2005) in which real estate was investing in ICTs, so were millions of consumers. By 2005, more than 70 percent of Americans were actively using the Internet, had computers in their homes, used them at work or school, and - perhaps more importantly-were aware that the Internet, computing, and digital information/communication had important implications for how people worked, lived and organized. A second aspect of this success in taking up and getting value from ICT arises from how real estate agents do their work. That is, much of the work done by real estate agents and professionals is localized and personal. As Crowston et al. (2001) detail, real estate processes are fluid and localized, putting the focus of innovation at the individual, not institutional level.

In general, the data presented and discussed here make clear that information-based services such as real estate rely on the concepts of coinvention (see Bresnehan and Greenstein 2001). This suggests that more micro-studies, focused on particular markets, technologies, and activities, are needed. These studies will amplify and help to explain variations among industries (due perhaps to differences in policy regimes, level of regulation, etc.). Melding macro-level analyses and micro-studies together will provide more empirical clarity and reduce the theoretical and conceptual preaching that seems to happen in the absence of good data.

A second area for future work would be to focus on the kinds of ICT being used in supporting services. For example, there is a clear trend in hospitals toward large-scale, enterprise-wide packages that provide a semiautomated administrative infrastructure to support operations. The uses of these types of systems have been documented in the manufacturing and fabricated products industry for nearly 30 years. However, in the legal industry, there is a growing use of personal computing and common shared information infrastructures, particularly as courts become more digitally enhanced. In the securities industry, there is a growth in large-scale programmed trading and individualized decision-support systems. And, relative to the empirical domain we use in the paper, the modest level of micro-scale data on ICT uses in real estate suggests computerization differs from these approaches.

\section{Acknowledgments}

This paper is much improved by comments to prior draft by Paul Bishop, Kevin Crowston, Rolf Wigand, Elizabeth Davidson, and three anonymous reviewers. This work is supported in part by funding from the U.S. National Association of Realtors and the U.S. National Science Foundation.

\section{References}

Bresnehan, T., and Greenstein, S. 2001. "The Economic Contribution of Information Technology: Towards Comparative a User Studies," Journal of Evolutionary Economics (11), pp. 95-118. 
Burris, B. 1998. “Computerization of the Workplace," American Review of Sociology (24), pp. 141-157.

Carmel, E. 1997. "American Hegemony in Packaged Software Trade and the 'Culture of Software," The Information Society (13:2), pp. 125-142.

Chesbrough, H., and Spohrer, J. 2006. “A Research Manifesto for Services Science," Communications of the ACM (49:7), pp. 35-49.

Ciborra, C. 1996. "The Platform Organization: Recombining Strategies, Structures, and Surprises," Organization Science (7:2), pp. 103-118.

Crowston, K., Sawyer, S., and Wigand, R. 2001. "The Interplay Between Structure and Technology: Investigating the Roles of Information Technologies in the Residential Real Estate Industry," Information Technology \& People (14:2), pp. 163-183.

Dumagan, J., Gill, G., and Ingram, C. 2003. "Industry Level Effects of IT Use on Productivity and Inflation," in Digital Economy, D. Evans (ed.), Cheltenham, UK: Edgar Algar, pp. 41-60.

Metka, S., Jaklic, A., and Kotnik, P. 2006. "Exploiting ICT Potential in Service Firms in Transition Economies," The Service Industries Journal (26:3), pp. 287-299.

Rust, R., and Miu, C. 2006. "What Academic Research Tells Us About Service," Communications of the ACM (49:7), pp. 49-54.

Sawyer, S., Crowston, K., Wigand, R., and Allbritton, M. 2003. "The Social Embeddedness of Transactions: Evidence from the Residential Real Estate Industry," The Information Society (19:2), pp. 135-154.

Sawyer, S., Wigand, R., and Crowston, K. 2005. "Redefining Access: Uses and Roles of Information and Communications Technologies in the Residential Real Estate Industry from 1995-2005," Journal of Information Technology (20:4), pp. 3-14.

Sheehan, J. 2006. "Understanding Service Sector Innovation," Communications of the ACM (49:7), pp. 42-47.

Sproul, L., and Kiesler, S. 1991. Connections: New Ways of Working in the Networked Organization, Cambridge, MA, MIT Press.

Wolff, E. 2002. "Productivity, Computerization and Skill Change," Federal Reserve Bank of Atlanta Economic Review, pp. 63-78.

\section{About the Authors}

Steve Sawyer is a founding member and an associate professor at the Pennsylvania State University's College of Information Sciences and Technology. Steve holds affiliate appointments in the department of Management and Organization, the department of Labor Studies and Employer Relations, and the program in Science, Technology and Society. Steve does social and organizational informatics research with a particular focus on people working together using information and communication technologies. Steve can be reached at sawyer@ist.psu.edu.

Fuyu Yi is a master's student in the Pennsylvania State University's Department of Labor Studies and Employer Relations. Fuyu's research focuses on the implications and uses of information and communication technologies relative to work and organizing. Fuyu's email is fuy101@psu.edu. 